\title{
UJI STABILITAS PENYIMPANAN IKAN PEPEREK (Leiognathus equulus) KERING DENGAN METODE PENGEMASAN YANG BERBEDA
}

\author{
Storange stability test of peperek dry fish (Leiognathus equulus) with different paci _ ing methods
}

\author{
Rusnawati ${ }^{\star}$, Haslianti, Suwarjoyowirayatno \\ Jurusan Teknologi Hasil Perikanan, Fakultas Perikanan dan Ilmu Kelautan Universitas Halu Oleo, Kendari, \\ Sulawesi Tenggara, Indonesia \\ *Email korespondensi: rusnawati0898@gmail.com (Telp: +6282259960968) \\ Diterima: 15 Maret/ Disetujui 19 Oktober 2020
}

Cara sitasi: Rusnawati, Haslianti, Suwarjoyowirayatno. 2020. Uji stabilitas penyimpanan ikan peperek (Leiognathus equulus) kering dengan metode pengemasan yang berbeda. Jurnal Fish Protech. 3(2):178-183.

\begin{abstract}
The aims of this study was to determine the storage stability test of dried peperek fish (Leiognathus equulus) with different packaging methods. This study used a randomized block design (RBD) consisting of 2 treatment factors. The first treatment factor is PE plastic packaging (VO) and aluminum foil plastic packaging (V1). The second treatment factor is storage time which consists of 4 levels, namely $\mathrm{H} 1$ (1 day), $\mathrm{H} 2$ (7 days), $\mathrm{H3}$ (14 days) and $\mathrm{H} 4$ (21 days). Test parameters include organoleptic tests (appearance, aroma, and texture), TPC and moisture content. Based on the results, it showed that the effect of storage time of PE plastic packaging and aluminum foil plastic packaging on organoleptic tests is appearance $V_{0} T_{14} 8.32, V_{1} H_{1} 6.64$, aroma $V_{0} T_{14} 8.36, V_{1} H_{1} 3.69$, texture $V_{0} T_{14} 8.52, V_{1} H_{1} 4$. while the best moisture content test results are found in $V_{1} H_{14}$ with the lowest value of $13.94 \%$, and lowest TPC content in $V_{1} H_{14}$ with the lowest value of $1.46 \times 10^{5}$.
\end{abstract}

Keywords: fish peperek (leiognathuus equlus), Total Plate Count TPC, water content test, and organoleptic

\begin{tabular}{l} 
ABSTRAK \\
\hline Penelitian ini bertujuan untuk mengetahui uji stabilitas penyimpanan ikan peperek (Leiognathus equulus) kering \\
dengan metode pengemasan yang berbeda. Penelitian ini menggunakan rancangan acak kelompok (RAK) yang terdiri \\
dari 2 faktor perlakuan. Faktor perlakuan pertama yaitu kemasan plastik pe $\left(\mathrm{V}_{0}\right)$ dan kemasan plastik aluminium foil $\left(\mathrm{V}_{1}\right)$. \\
Faktor perlakuan kedua adalah waktu penyimpanan yang terdiri dari 4 taraf yaitu $\mathrm{H}_{1}\left(1\right.$ hari), $\mathrm{H}_{2}\left(7\right.$ hari), $\mathrm{H}_{3}(14$ hari) dan \\
$\mathrm{H}_{4}(21$ hari). Parameter uji meliputi Uji organoleptik (kenampakan, aroma, dan tekstur), $\mathrm{TPC}$ dan kadar air. Berdasarkan \\
hasil penelitian, menunjukkan bahwa pengaruh lama penyimpanan kemasan plastik $P E$ dan kemasan plastik aluminium \\
foil terhadap uji organoleptik yaitu kenampakan $\mathrm{V}_{0} \mathrm{~T}_{14} 8.32, \mathrm{~V}_{1} \mathrm{H}_{1} 6.64$, aroma $\mathrm{V}_{0} \mathrm{~T}_{14} 8.36, \mathrm{~V}_{1} \mathrm{H}_{1} 3.69$ tekstur $\mathrm{V}_{0} \mathrm{~T}_{14} 8.52$, \\
$\mathrm{V}_{1} \mathrm{H}_{1} 4$. sedangkan hasil uji kadar air terbaik terdapat pada $\mathrm{V}_{1} \mathrm{H}_{14}$ dengan nilai terendah $13.94 \%$, dan kandungan $\mathrm{TPC}$ \\
terendah $\mathrm{V}_{1} \mathrm{H}_{14}$ dengan nilai terendah $1.46 \times 10^{5}$.
\end{tabular}

Kata kunci: Ikan peperek (leiognathuus equlus), Total Plate Count TPC, uji kadar air, dan uji organoleptik

\section{PENDAHULUAN}

Ikan peperek merupakan ikan demersal yang menjadi salah satu penyusun komunitas ikan diperairan Teluk Kendari (Asriyana et al., 2009). Ikan ini termaksud dalam famili Leiognathidae memiliki nilai yang cukup ekonomis sehingga nelayan cenderung mengeksploitasi sumber daya ini dalam jumlah yang besar. Jenis ikan ini merupakan ikan yang hidup di dasar perairan hingga mencapai permukaan (benthopelagik) sebagian besar hidup di laut dan beberapa di air payau. Secara ekologis ikan peperek sebagai ikan pemakan plankton yang sangat memengaruhi rantai makanan dalam ekosistem.

Umumnya ikan memiliki kadar air yang tinggi demikian pula ikan peperek yang mengandung 
$77,07 \%$ kadar air (Nugroho, 2006). Kadar air yang tinggi pada tubuh ikan, merupakan media yang baik untuk pertumbuhan mikroba, hal ini menunjukkan produk perikanan mudah sekali busuk, karena itu dilakukan pengolahan dan pengawetan. Salah satu cara pengawetan ikan, dpat di lakukan dengan proses pengeringan ikan dengan penjemuran di bawah sinar matahari atau dengan oven. Pengeringan dengan menggunakan oven memiliki keuntungan yaitu suhu dan waktu pemanasan dapat diatur. Dengan oven buatan sendiri, ikan asin dapat diproduksi dengan kapasitas yang lebih banyak. Pengeringan menggunakan panas matahari selain biaya murah, juga mempunyai daya tampung yang besar. Akan tetapi cara ini sangat tergantung pada cuaca dan suhu pengeringan tidak dapat diatur (Suwarno et al., T .2008).

Ikan kering merupakan produk pengolahan hasil perikanan yang cukup mudah dalam pembuatannya. Pengeringan merupakan cara pengawetan ikan dengan mengurangi kadar air pada tubuh ikan sebanyak mungkin (Alim, 2004).

Umumnya ikan memiliki kadar air yang tinggi demikian pula ikan peperek yang mengandung $77,07 \%$ kadar air (Nugroho, 2006). Kadar air yang tinggi pada tubuh ikan, merupakan media yang baik untuk pertumbuhan mikroba, hal ini menunjukkan produk perikanan mudah sekali busuk, karena itu dilakukan pengolahan dan pengawetan.

\section{Rancangan Penelitian}

Rancangan penelitian yang digunakan yaitu rancangan acak kelompok dengan dua kelompok. Kelompok pertama yaitu kemasan (aluminium foil dan kemasan plastik) dan kelompok ke dua yaitu penyimpanan $(1,7,14,21$ hari).

\section{Parameter Uji}

Prosedur penelitian ini dilakukan dengan beberapa tahap di antaranya yaitu persiapan penelitian, uji organoleptik, kadar air, dan uji total bakteri (TPC), penelitian perubahan mutu ikan
Ikan peperek kering merupakan ikan yang cepat mengalami kerusakan dimana selama ini belum ada penanganan mengunakan kemasan terhadap ikan peperek kering. dengan metode pengolahan seperti ini produk tidak terjamin daya awetnya untuk jangka waktu yang di kehendaki. Untuk dapat mempertahankan mutu ikan peperek kering maka perlu di lakukan dengan metode pengemasan sehingga berdampak pada perpanjangan umur simpan. Kemasan dengan daya hambat gas yang baik dan luas permukaan yang lebih kecil menyebabkan masa simpan produk lebih lama (Bukle et al., 1987).

\section{METODE PENELITIAN}

\section{Alat dan Bahan}

Alat yang digunakan dalam uji stabilitas penyimpanan ikan peperek kering yaitu, Alat untuk uji Kadar Air menggunakan oven, cawan kosong, desikator, timbangan. Alat yang digunakan untuk uji TPC yaitu tabung reaksi, pipet tetes, cawan petri.

Bahan yang digunakan dalam pengemasan ikan peperek kering yaitu ikan peperek (yang di peroleh dari pedagang), kemasan plastik $\mathrm{PE}$, dan kemasan aluminium foil. Bahan analisis yang digunakan uji kadar air yaitu sampel ikan peperek, dan bahan yang digunakan untuk uji TPC meliputi nutrient agar dan aquades.

peperek kering yang dikemas plastik PE dan kemasan aluminium foil di simpan selama 1, 7, 14, 21 hari pada suhu ruang.

\section{Analisis Data}

Data hasil penelitian organoleptik dianalasi menggunakan sidik ragam ANOVA (Analysis of variance), jika terdapat perbedaan yang sangat nyata kemudian akan diuji lanjut menggunakan uji DMRT (Duncan multiple range test) dengan taraf kpercayaan $95 \%(a=0,05)$ 


\section{HASIL DAN PEMBAHASAN}

Hasil pengamatan terhadap uji stabilitas penyimpanan ikan peperek (leiognathus equulus) kering dengan metode pengemasan yang berbeda dapat dilihat pada tabel dibawah ini.

Tabel 1. Hasil analisis uji organoleptik

\begin{tabular}{|c|c|c|c|}
\hline Perlakuan & $\begin{array}{l}\text { rerata kenampakan } \\
\pm S D \text { (kategori) }\end{array}$ & $\begin{array}{l}\text { rerata bau } \\
\pm \mathrm{SD} \text { (kategori) }\end{array}$ & $\begin{array}{l}\text { rerata tekstur } \\
\pm S D \text { (kategori) }\end{array}$ \\
\hline$V_{0}$ & $\begin{array}{l}5.25^{a} \pm 0.57 \\
\text { (sedikit rusak fisik, } \\
\text { kurang bersih, } \\
\text { Beberapa bgian rusak) }\end{array}$ & $\begin{array}{l}5.32 \mathrm{a} \pm 0.96 \\
\text { (bau tambahan menganggu, } \\
\text { tidak busuk, sedikit bau) }\end{array}$ & $\begin{array}{l}4.89^{\mathrm{a}} \pm 1.85 \\
\text { (padat, basah, tidak } \\
\text { tidak mudah terurai) }\end{array}$ \\
\hline$V_{1}$ & $\begin{array}{l}7.23^{b} \pm 0.89 \\
\text { (utuh, bersih, agak kusam }\end{array}$ & $\begin{array}{l}6.66^{b} \pm 1.36 \\
\text { (netral, sedikit bau tambahan) }\end{array}$ & $\begin{array}{l}6.90^{\mathrm{b}} \pm 1.89 \\
\text { (padat tidak terurai) }\end{array}$ \\
\hline
\end{tabular}

Tabel 2. Nilai hasil analisis uji kadar Air dan uji TPC

\begin{tabular}{|c|c|c|c|c|}
\hline \multirow[t]{2}{*}{ No } & \multirow[t]{2}{*}{ variabel Pengamatan } & \multicolumn{2}{|c|}{ Perlakuan } & \multirow{2}{*}{$\begin{array}{c}\text { Standar SNI } \\
\text { 2771: } 2009 \\
(\mathrm{Cfu} / \mathrm{gr})^{*}\end{array}$} \\
\hline & & $\begin{array}{c}\text { Kemasan plastik PE } \\
\left(\mathrm{V}_{0} \mathrm{H}_{14}\right)\end{array}$ & $\begin{array}{l}\text { Kemasan aluminium foil } \\
\left(\mathrm{V}_{1} \mathrm{H}_{14}\right)\end{array}$ & \\
\hline 1. & Kadar air & $15.51 \%$ & $13.94 \%$ & \\
\hline 2. & TPC & $1.67 \times 10^{5}$ & $1.46 \times 10^{5}$ & $1.0 \times 10^{5}$ \\
\hline
\end{tabular}

${ }^{*} \mathrm{BSN}(2009)$

\section{Uji Organoleptik Kenampakan}

Kenampakan merupakan salah satu parameter organoleptik yang penting dalam produk ikan peperek kering. Berdasarkan hasil rerata interaksi kenampakan ikan peperek kering dengan teknik pengemasan yang berbeda dan waktu penyimpanan menunjukkan nilai tertinggi pada perlakuan $\mathrm{V}_{0} \mathrm{~T}_{14}$ dengan nilai 8.32 dan nilai terendah pada perlakuan $\mathrm{V}_{1} \mathrm{H}_{1}$ 4.64. Bahan pangan yang diasinkan dan dilanjutkan dengan pengeringan sering mengalami oksidasi lemak, apalagi jika memiliki kandungan lemak yang tinggi. Menurut winarno (2002) penurunan kenampakan dikarenakan aktifitas bakteri sedangkan perlakuan menggunakan kemasan mampu memperlambat penurunan parameter kenampakan. hal ini di karenakan tidak adanya udara dalam kemasan maka pertambahan bakteri akan melambat.

\section{Aroma}

Aroma merupakan salah satu parameter organoleptik yang penting dalam produk ikan peperek kering. Bau dapat mengevaluasi aroma produk dan dibutuhkan dalam memberikan penilaian terhadap aroma. Hasil rerata interaksi tekstur ikan peperek kering dengan teknik pengemasan yang berbeda dan waktu penyimpanan menunjukkan nilai tertinggi pada perlakuan $\mathrm{V}_{0} \mathrm{H}_{14} 8.36$ dan nilai terendah pada perlakuan $\mathrm{V}_{1} \mathrm{H}_{1}$ 3.69. Penyebabnya diduga karena proses oksidasi yang belum berlanjut sehingga ketengikan terhambat prosesnya. sehingga proses perombakan lemak oleh enzim dapat melambat. Lestary (2007) menyatakan bahwa, perubahan atau penguraian lemak dapat mempengaruhi bau dan rasa suatu bahan makanan khususnya pada masa penyimpanan, sehingga kerusakan lemak dapat menurunkan nilai gizi serta menyebabkan penyimpangan bau dan rasa. Sedangkan teknik pengemasan dan interaksi berpengaruh sangat nyata. (Winarno 1997).

\section{Tekstur}

Hasil rerata interaksi tekstur ikan peperek kering dengan teknik pengemasan yang berbeda dan waktu 
penyimpanan menunjukkan nilai tertinggi pada perlakuan $\mathrm{V}_{1} \mathrm{H}_{14} 8.52$ dan nilai terendah pada perlakuan $\mathrm{V}_{0} \mathrm{H}_{1}$ 4. Hasil uji organoleptik pada waktu penyimpanan berpengaruh nyata, sedangkan teknik pengemasan dan interaksi berpengaruh sangat nyata. Menurut (Reo, 2012) tekstur pada pengemasan ikan peperek kering disebabkan terhadap perbedaan bahan kemasan yang di gunakan sehingga mempengaruhi warna produk ikan kering karna Tekstur berkaitan erat dengan kadar air pada bahan pangan. Pada ikan asin kering tekstur dipengaruhi oleh kadar air, kadar air yang rendah membuat konsistensi ikan asin kering menjadi lebih baik.

\section{Uji Kimia}

\section{Kadar Air}

Berdasarkan hasil dari pemilihan perlakuan terbaik terlihat bahwa nilai kadar air pada pengemasan produk ikan peperek kering dengan teknik pengemasan plastik PE dan plastik aluminium foil adalah $\mathrm{V}_{0} \mathrm{H}_{14} 14.51 \%$ dengan nilai tertinggi kadar air dan $\mathrm{V}_{1} \mathrm{H}_{14}$ dengan nilai terendah $13.94 \%$. Hal ini didukung oleh peneltian Sukawati (2005), menyatakan bahwa kenaikan kadar air bahan pangan dalam kemasan di pengaruhi oleh premeabilitas uap air, sifat penyerapan uap air bahan pangan, dan kelembaban relative disekitar kemasan. Fardiaz (1992) menyatakan bahwa semakin sedikit bakteri yang tumbuh, maka jumlah air yang dihasilkan juga semakin rendah. Pembungkus plastik dapat mencegah kontaminasi langsung bakteri yang berasal dari udara dan tangan manusia. Penelitian ini serupa dengan penilitian Nopianti dan Utami Resqi (2016) tentang kadar air ikan kering asin sepat siam (trichogaster pectoralis) yang dikemas vakum dan non vakum hasil penelitian menunjukkan kadar air berkisar 29,30$39,02 \%$.

\section{Uji TPC (Total Plate Count)}

Berdasarkan hasil dari pemilihan perlakuan terbaik terlihat bahwa nilai uji TPC pada pengemasan produk ikan peperek kering dengan teknik pengemasan plastik PE dan plastik aluminium foil adalah $\mathrm{V}_{0} \mathrm{H}_{14} 1.67 \times 10^{5}$ dan $\mathrm{V}_{1} \mathrm{H}_{14} 1.46 \times 10^{5}$. masing- masing perlakuan dinyatakan tidak memenuhi standar mutu yang di tetapkan untuk TPC ikan kering yaitu sebanyak $1,0 \times 10^{5}$ (BSN. 2009). Hal ini didukung oleh pernyataan Nurrochyani (1994) faktor yang mempengaruhi adanya mikroba adalah faktor instriksik dan faktor ekstrinsik. Faktor instrinsik adalah faktor yang tidak dapat dikendalikan oleh usaha apapun juga dari manusia, artinya faktor yang berasal dari individu ikan itu sendiri misalnya adanya komponen zat makanan yang diperlukan oleh mikroba, pH daging ikan. faktor ekstrinsik merupakan faktor yang dapat dikendalikan oleh manusia didalam mempelajari kedua aspek tersebut, misalnya cara-cara penangkapan, pengambilan contoh, media pertumbuhan yang digunakan, dan suhu inkubasi. Menurut Susianawati et al. (2007) faktor yang mempengaruhi tingginya nilai TPC pada ikan asin kering yaitu kemungkinan air yang digunakan mencuci masih mentah atau belum mengalami proses sterilisasi atau ada pengaruh lingkungan. Penelitian ini serupa dengan penilitian Nawansih dan Rangga (2011) tentang uji mutu dan keamanan ikan asin kering (teri dan sepat) yang dikemas di pasar kota Bandar lampung hasil penelitian menunjukan uji TPC

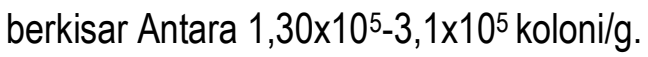

\section{KESIMPULAN}

1. Terdapat pengaruh penyimpanan ikan peperek (Leiognathus equulus) kering dengan metode pengemasan plastik PE. Hasil analisis ragam nilai organoleptik kenampakan ikan peperek kering menunjukkan hasil berbeda nyata dengan rerata nilai yang berkisar antara 5,25 , bau 5,32 dan tekstur 4,89. Hasil ananlisis kimia didapatkan bahwa nilai kadar air $15.51 \%$ dan TPC $1.67 \times 10^{5}$.

\section{Terdapat pengaruh penyimpanan ikan Peperek} (Leiognathus equulus) kering dengan metode pengemasan aluminium foil. Hasil analisis ragam nilai organoleptik kenampakan ikan peperek kering menunjukkan hasil berbeda nyata dengan rerata nilai yang berkisar antara 7,23 , bau 6,66 dan tekstur 6,89. Hasil ananlisis kimia didapatkan bahwa nilai kadar air $13.94 \%$ dan TPC $1.46 \times 10^{5}$. 


\section{DAFTAR PUSTAKA}

Association of Official Analytical Chemist (AOAC). 2005. Oficial methods of Analisis. Washington DC.

Allo YB.1998.Selektifikasi Trammel Net terhadap ikan pepetek di perairan teluk pelabuhan ratu , sukabumi, jawa barat. [Skripsi], Bogor: Fakultas Perikanan dan IImu Kelautan, Institut Pertanian. Bogor.

Alim, E. 2004. Mutu Cita Rasa Rengginang Berbasis Beras Aromatik Dengan Metode Pengeringan Berbeda. [Skripsi]. Fakultas Teknologi Pertanian Institut Pertanian Bogor.

Asriyana, Raharjo, M.F, Djamartupal F, Lumpan Batu, Endi S, Kartamihardja. 2009, Komposisi Jenis dan Ukuran Ikan Petek (Famili Leiognathidae) di Teluk Kendari Sulawesi Tenggara, Jurnal Iktiologi Indonesia, 11 (1) :11-19.

Arpah M. 2001. Buku Dan Monograf Penentuan Kadaluarsa Produk Pangan. Bogor: Program Studi Ilmu Pangan.

Afrianto E,Liviawati E.2005. pengawetan pangan dan pengolahan ikan . Yogyakarta:kanisius

Badan Standardisasi Nasional. 2009. Syarat Mutu Ikan Asin Kering SNI 27211:2009

Badrudin, M. 1988. Parameter Stok dan Potensi Penangkapan Ikan Peperek di perairan Pantai Utara Jawa Tengah.Jurnal Penelitian Perikanan Laut 47 (1):87-95.

Benning, C.J. 1983. Plastic FilmFor Packinging. Technology Application and Process Economics. Technology Publishing Co. Inc. 851. New Holland Avenue Box 3535.Lancaster.Pennsylvania 17694.

Buckle, K.A., R.A., Edward, G.H. Fleet dan M. Wootton. 1987. IImu Pangan. (Penerjemah Purnomo, H., dan Adiono). Departemen Pendidikan dan Kebudayaan. Jakarta.

[BPPMHP] Balai pengembangan dan pengujian mutu Hasil perikanan. 2001. Instruksi kerja pengujian contoh hasil perikanan. Jakarta: laboratorium kimia BPPMHP departemen kelautan dan perikanan

Fardiaz, S.1996 Prinsi HACCP dalam industri pangan. Bogor: Teknologi Pangan dan gizi. Institut pertanian Bogor. Bogor.

Gandotra , R., S. Sharma, M. Koul, and S. Gupta. 2012. Effect of chilling and freezing on fish muscle. IOSR Journal of pharmacy and biological science, Vol 2 (5)

Hadiwiyoto, S. 2012. Hubungan Keadaan Kimiawi dan Mikrobiologik Ikan Pindang Naya Pada Penyimpanan Suhu Kamar Dengan Sifat Organoleptiknya. Agritech Volume 15 Nomor $1, \quad 2, \quad 3 . \quad$ dari http://jurnal.pdii.lipi.go.id/admin/jurnal/15123 951923.pdf.

Herawati H. 2008. Penentuan umur simpan produk pangan. Jurnal penelitian dan pengembangan pertanian. 27(4):124-130.

Hermanianto J, Arpah M, Jati WK. 2000. Penentuan umur simpan produk ekstrusi hasil samping penggilingan padi (menir dan bekatul) dengan menggunakan metode konvensional, kinetika Arrhenius dan sorpsi isothermis. Bul Teknol \& Ind Pang 11 (2):33-41.

Imdad, H. P. dan Nawangsih A. A. 1999. Menyimpan Bahan Pangan. Penebar Swadaya, Jakarta.

Icho, 2001, Re : (balita-anda) FW : Ikan Asin, http://www.balita anda/wed,28 Nov 2001 03:55:56-0800

Kusnandar, F. 2010. Kimia Pangan Komponen Makro Seri 1. Dian Rakyat. Jakarta.

Lestary, M. 2007. Pemanfaatan Biji Picung (Pangium Edule Reinw.) dan Kitosan sebagai Alternatif Pengganti Formalin pada Proses Pengawetan Ikan Cucut (Charcharimus Sp.) AsindiMuaraAngke,JakartaUtara.darihttp://re pository.ipb.ac.id/bitstream/handle/1234567 89/48567/C07mle.pdf?sequence=1. Desember 2012].

Masyamsir, 2001. Penanganan Hasil Perikanan. Departemen Pendidikan Nasional. Jakarta.

Moelyanto. 1992. Pengawetan dan Pengolahan Hasil Perikanan. Penebar Swadaya. Jakarta

Margono T. 1983 Buku panduan teknologi pangan pusat informasi wanita dalam

Pembanguna PDII-LIPI berkerjasama dengan swiss development cooperation, Jakarta.

Mainaliza, I. 2003. Studi Pengolahan Burger Ikan Jambal Siam (Pangasius sutchi) Denagan Jenis dan Berat lkan yang Berbeda. [Skripsi] Fakultas Perikanan dan IImu Kelautan Universitas Riau. (diterbitkan).

Nawansih Otik. et all. 2017. Uji mutu dan keamanan Ikan asin kering (teri dan sepat) di pasar kota 
Bandar lampung. Alumni Jurusan Teknologi Hasil Pertanian, Fakultas Pertanian, Universitas Lampung. Bandar lampung.

Nurrochyani. 1994. Dasar-Dasar Teknologi Ikan, Bahan Mata Kuliah Mahasiswa

Akademi Perikanan Yogyakarta : Yogyakarta.

Nugroho JS. 2006 optimalisai pemanfaatan ikan peperek (leiognathus sp.) dan ubi jalar putih (ipomoeae batatas $L$ ) untuk subtitus parsial tepung terigu dalam pembuatan biscuit. Fakultas perikanan dan ilmu kelautan. Institu pertanian bogor. bogor

Rahmadana. 2013. Masa Simpan Rendang ikan dalam kemasan Vakum selsma penyimpanan suhu Ruang dan Dingin. [Skripsi] Fakultas Pertanian. Universitas Hasanuddin. Makassar. 52-59 hal.

Rodiana, Nopianti dan Resqi 2016. Umur simpan ikan asin sepat siam (trichogaster pectoralis) duri lunak dengan pengemasan vakum dan non vakum pada penyimpanan suhu ruang. Prosiding Seminar Nasional Lahan Subaptimal 20016. Palembang

Ristanti, R., 2010. Mempelajari Keawetan Tempe Pasteurisasi dalam Kemasan Vakum HDPE dan Aluminium Foil. Thesis, Sekolah Pascasarjana, Institut Pertanian Bogor : Bogor.

Syarief, R dan Halid, H. 1993. Teknologi Penyimpanan Pangan. IPB. Bogor.

Syarief R., Sassya, S., dan Isyana, B.S.T.1989. Teknologi Pengemasan Pangan. Laboratorium rekayasa proses pangan PAU pangan dan gizi. IPB. Bogor.

Saanin, H. 1984. Taksonomi dan kunci identifikasi ikan. Bogor. Bogor: Bina cipta

Suwetji, I.K, 1993. Metode penentuan mutu ikan: Penentuan kesegaran, jilid 1, Fakultas Perikanan Unsrat Manado.

Sukawati, E.D. 2005. Penentuan umur simpan biji dan bubuk lada hitam dengan metode akselerasi. Skripsi. Fateta. IPB, Bogor.

Susianawati, R., L., Sya'rani, dan Winarniagustini. 2007. Kajian Penerapan GMP dan SSOP Pada Produk Ikan Asin Kering dalam Upaya Peningkatan

Soeparno. 1994. IImu dan teknologi daging. UGM press Yogyakarta

Suwarno dan prasetyo, T .2008. Pembuatan Alat Pengering Ikan Tri Hitam Dengan Sistem
Udara Hembus Berktapasitas $12 \mathrm{Kg}$ Ikan Basah. Jurnal Orbi.4(3):436-441

Szczesniak AS. 2002. Tekstur is asensory property. Food quality and preference 13: 215-225

Pinem, M. Daud. 2004. Rancang Bangun Alat Pengering Ikan Teri Kapasitas 12 kg/jm. usuir vol.no3 (3) desember

Wigati, D.2009. Pengaruh Jenis Kemasan dan Lama Penyimpanan terhadap Serangan Serangga dan Sifat Fisik Ransum Broiler Starter Berbentuk Crumble. Skripsi. Departemen IImu Nutrisi dan Teknologi Pakan Fakultas Peternakan. Institut Pertanian Bogor. Bogor. 